\title{
Setting Shrinkage and Hygroscopic Expansion of Resin-modified Glass-ionomer in Experimental Cylindrical Cavities
}

\author{
Young-gill KIM and Susumu HIRANO \\ Department of Dental Engineering, Tsurumi University \\ School of Dental Medicine, 2-1-3 Tsurumi, Tsurumi-ku, \\ Yokohama 230-8501, Japan
}

Received September 16, 1998/Accepted December 14, 1998

\begin{abstract}
The effects of the C-value (bonded surface area/unbonded surface area) and the volume of the cavity on the volumetric dimensional changes [volumetric setting shrinkage (VSS) and volumetric hygroscopic expansion (VHE)] of a resin-modified glass-ionomer (RMGI) filled in experimental cylindrical cavities were evaluated.

The VSS and the VHE rate decreased with increasing C-value. There was a high inverse regression between the cavity $\mathrm{C}$-value and volumetric dimensional changes, but a low regression between cavity volume and volumetric dimensional changes. Therefore, it was thought that greater contraction stress would remain in high $\mathrm{C}$-value cavities than low $\mathrm{C}$-value cavities during the setting process. It was also confirmed that the volumetric dimensional changes of RMGI in cavity were influenced primarily by the cavity $\mathrm{C}$-value.
\end{abstract}

Key words : Resin-modified glass-ionomer, Setting shrinkage, Hygroscopic expansion

\section{INTRODUCTION}

Restorative materials filled in cavities are immobilized by bonding to the cavity wall, if they have bonding ability to the tooth substrates. In such conditions, contraction stress occurs at the adhesive interface or in the material itself during the setting process due to the setting shrinkage, and that stress may become a cause of restoration failure. Feilzer et al. ${ }^{1}$ who investigated the factors which affect the development of contraction stress in resin composites in the restricted conditions, and suggested that there is a high correlation between the contraction stress and the ratio of the bonded surface area to unbonded (free) surface area in a restored cavity. They introduced a ratio known as the $\mathrm{C}$-value to generalize various types of cavities in relation to contraction stress. Some studies ${ }^{1-3)}$ also showed that the contraction stress became greater with increasing $\mathrm{C}$-value, and that restoration success or durability would be affected by the cavity C-value.

Resin-modified glass-ionomers (RMGIs) show not only superior bond strength to tooth substrates ${ }^{4-6)}$, but also a high setting shrinkage ${ }^{6,7)}$ due to polymerization of HEMA (2-hydroxyethyl methacrylate) which is incorporated as a resin component. Therefore, in restorations using RMGI, contraction stress would be generated at the adhesive interface and within the material itself during the setting process. Although the contraction stress of RMGI in the cavity is expected to be substantially lower than that of resin composites, some studies $^{8-12)}$ have shown adhesive and cohesive 
failures of RMGI restorations. Therefore, the contraction stress would affect RMGI restoration success as predicted by the cavity $\mathrm{C}$-value, just as with resin composites. In addition, because the contraction stress arises from the setting shrinkage of materials, the setting shrinkage is also influenced by the cavity $\mathrm{C}$-value.

While there have been reports ${ }^{8-12)}$ on adhesive failure of RMGI by contraction stress, manufacturers and several studies ${ }^{13-15)}$ advocate good marginal adaptability of RMGI. This good adaptability is due to decreased contraction stress resulting from flow during the setting process ${ }^{2,3,9)}$ and complete relaxation of residual stress by hygroscopic expansion ${ }^{9,14}$. Therefore, it is thought that the hygroscopic expansion of RMGI is a important property in decreasing restoration failure. However, there are few studies on the factors affecting hygroscopic expansion of restorative materials in cavities.

As described previously, the dimensional changes of RMGI- setting shrinkage and hygroscopic expansion- are very important for restoration success. In recent years, many studies have evaluated the dimensional changes of $\mathrm{RMGI}^{14-17)}$. However, few investigators have examined the factors which have an effect on dimensional changes in filled cavities, despite their clinical importance. The purpose of the present study was to clarify the effects of $\mathrm{C}$-value and cavity volume on volumetric setting shrinkage (VSS) and volumetric hygroscopic expansion (VHE) of RMGI in experimental cylindrical cavities. The cavity $\mathrm{C}$-value is defined by the following equation; $\mathrm{C}$ value $=$ bonded surface area/unbonded surface area $=\left(\pi r^{2}+2 \pi r \times h\right) / \pi r^{2}=(r+2 h) /$ $\mathrm{r}=1+2 \mathrm{~h} / \mathrm{r}$, where $\mathrm{h}$ and $\mathrm{r}$ are the cavity depth and cavity radius, respectively. The behavior of setting shrinkage and hygroscopic expansion in cavity was also studied.

\section{MATERIALS AND METHODS}

\section{Preparation of specimens}

Table 1 shows the Fuji II LC (FJL) used in the present study as RMGI. According to previous studies ${ }^{4-6,18-20)}$, FJL has a superior bond strength to both enamel and dentin compared with other RMGIs, and also shows great dimensional changes ${ }^{6,7,21,22)}$. Therefore, it was thought that the effect of the cavity $\mathrm{C}$-value on dimensional changes would be more apparent in FJL than in other RMGIs. Also, as there is less error in measured results with symmetrical cavities than that with non-symmetrical cavities, and due to the difficulty in preparing clinical cavities with a constant $\mathrm{C}$-value, simple cylindrical cavities were used for the present study.

Table 1 Material used in the present study

\begin{tabular}{cccccc}
\hline Material & Code & Lot. No & Shade & Type & P/L $(\mathrm{g} / \mathrm{g})$ \\
\hline Fuji II LC & FJL & P: 011071 & A2 & Resin-modified & $3.0: 1.0$ \\
& & L: 300971 & & & \\
& & C: 250771 & & & \\
\hline
\end{tabular}

${ }^{1}$ GC. Co. Ltd., Tokyo, Japan

P: powder L: liquid C: conditioner 
Table 2 Experimental cavities used in the present study

\begin{tabular}{|c|c|c|c|c|}
\hline Radius & 1.0 & 1.5 & 2.0 & 2.5 \\
\hline 4.0 & $\begin{array}{c}\text { Cavity A } \\
\text { C: } 1.5 \\
\text { V: } 50.24\end{array}$ & & & \\
\hline 2.8 & $\begin{array}{c}\text { Cavity B } \\
\text { C: } 1.7 \\
\text { V: } 24.62 \\
\end{array}$ & $\begin{array}{c}\text { Cavity D } \\
\text { C: } 2.1 \\
\text { V: } 36.93 \\
\end{array}$ & $\begin{array}{c}\text { Cavity E } \\
\text { C: } 2.4 \\
\text { V: } 49.24 \\
\end{array}$ & \\
\hline 2.0 & $\begin{array}{c}\text { Cavity C } \\
\text { C: } 2.0 \\
\text { V: } 12.56\end{array}$ & & $\begin{array}{c}\text { Cavity G } \\
\text { C: } 3.0 \\
\text { V: } 25.12\end{array}$ & \\
\hline 1.6 & & & & $\begin{array}{c}\text { Cavity I } \\
\text { C: } 4.0 \\
\text { V: } 20.10\end{array}$ \\
\hline 1.5 & & $\begin{array}{c}\text { Cavity } \mathrm{F} \\
\mathrm{C}: 3.0 \\
\mathrm{~V}: 10.60 \\
\end{array}$ & & \\
\hline 1.3 & & & $\begin{array}{c}\text { Cavity } \mathrm{H} \\
\text { C: } 4.0 \\
\text { V: } 10.60\end{array}$ & \\
\hline
\end{tabular}

1. The unit of diameter and depth is $\mathrm{mm}$

2 . $\mathrm{V}$ means cavity volume, and the unit is $\mathrm{mm}^{3}$

3. C means C-value [ = bonded surface area/unbonded surface area $=(r+2 h) /$ $\mathrm{r}=1+2 \mathrm{~h} / \mathrm{r}]$

Freshly extracted 1st or 2nd mandibular bovine incisor crowns were mounted in acrylic self-cured resin. The mounted specimens were then ground with wet silicon carbide papers up to 700 grit to expose the intact enamel planes. Thereafter, a simple cylindrical cavity was prepared on the exposed surface with air turbine burs (No.111 and 301, Shofu, Japan) and contra-angle handpiece burs (No.14b, 18a, 18b and 19c, Shofu, Japan). In this study, as shown in Table 2, nine kinds of cavity (cavity A I) with different depths and radii were used. After completion of cavity preparation, the dimensions of each cavity were measured with a degimatic indicator (CD-15C, Mitutoyo, Japan). The diameter of the cavity was measured at four points, and the depth at five points. Prepared specimens were chosen allowing for errors of up to $\pm 0.1 \mathrm{~mm}$ in each group cavity dimension. They were then cleaned with an ultrasonic cleaner, and dried with air blowing. The cavities were treated with dentin conditioner according to the manufacturer's instructions, and filled with FJL as shown in Fig. 1. After slight over filling with no air trapping, the cement surface was covered with a polyester strip and a slide glass, and pressured by hand and with clamps. All specimens were then irradiated for $90 \mathrm{~s}$ with a curing unit (Dentacolar XS, Kulzer Co., Germany). 


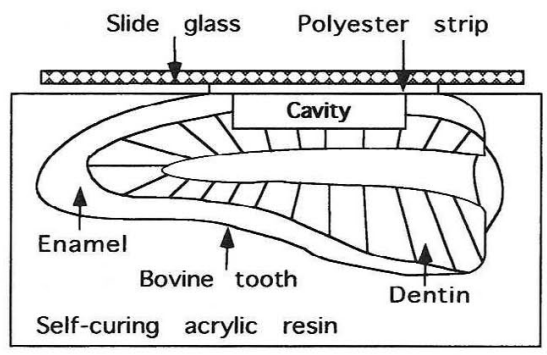

Fig. 1 Schematic illustration of a specimen.
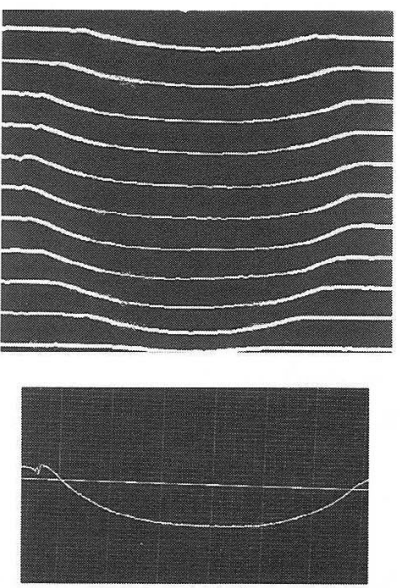

(a) Setting shrinkage
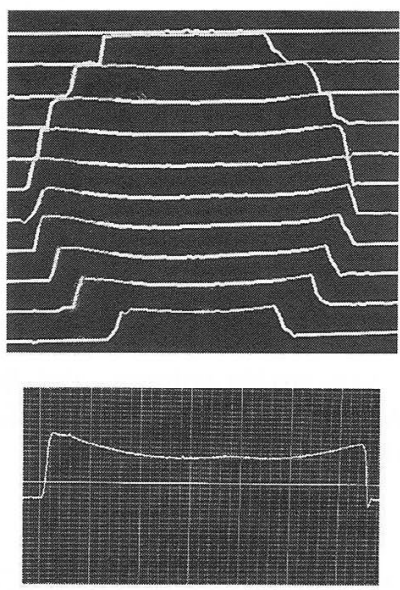

(b) Nominal hygroscopic expansion

Fig. 2 Photographs of two dimensional and three dimensional views after measuring of setting shrinkage and nominal hygroscopic expansion.

\section{Measurements of setting shrinkage and hygroscopic expansion}

FJL is a dual-cure type filling material. The two curing mechanisms are setting by acid-base reaction and radical polymerization of HEMA. According to some studies $^{19,23,24}$, the acid-base reaction would occur after the polymerization of HEMA. Also, in the present study, all specimens showed time elapsed shrinkage during the VSS measurement. However, the shrinkage stabilized approximately $40 \mathrm{~min}$ after the start of measuring. So, it was thought that VSS measurement was preferable after stabilization of the acid-base reaction, and the measurement was conducted $45 \mathrm{~min}$ after the start of irradiation.

After water storage for measuring of hygroscopic expansion, FJL shows high water absorption by the incorporated hydrophilic HEMA-polymer ${ }^{6}$. In this study, all nominal hygroscopic expansion (NHE) measurements were conducted in air at room 
temperature. Therefore, the measured NHE may be affected by dehydration during the measuring time. However, because the measuring was started within 5 min after removal from the distilled water and the largest cavity could be measured within about $18 \mathrm{~min}$, it was thought that the effect of measuring time on NHE would not be great.

The measurements of the VSS and NHE were conducted with a no contact laser profilometer (Surfcom 590A-3DF, Tokyo Seimitu, Japan). Fig. 2(a) and (b) show examples of the results of VSS and NHE measured using this machine. A twodimension sectional view was obtained from the height difference between data points at regular intervals (interval of $\mathrm{X}$ axis) and reference point, and a three-dimensional view was made of some two-dimension sectional views which were measured at regular intervals (interval of $\mathrm{Y}$ axis). However, because the experimental cavities used in the present study differed in size, as shown in Table 2, the measuring intervals of the $\mathrm{X}$ and $\mathrm{Y}$ axis were adjusted for similar measuring time to eliminate errors in the measured results caused by the different measuring times.

After the end of the VSS measurement, the excess FJL around the cavity was removed because it makes NHE measurement impossible after water immersion. The specimens were then stored in a bottle with distilled water at $37^{\circ} \mathrm{C}$ for $14 \mathrm{~d}$ to ensure complete hygroscopic expansion; studies $^{6,25)}$ have shown that water diffusion completes within about $8 \mathrm{~d}$. After the $14 \mathrm{~d}$ water storage, NHE measurement was conducted using the same method as for VSS measurement.

As the methods ${ }^{26,27)}$ used representative scan lines in the measured result to calculate wear amount, in this study three lines were chosen to obtain forty three data points as shown in Fig. 3; line B in the center, and lines $\mathrm{A}$ and $\mathrm{C}$ in the margin portion of the cavity which were each about half the length of line B. To obtain the mean values of setting shrinkage depth and hygroscopic expansion height with each baseline, forty three data points; eleven in each of lines $\mathrm{A}$ and $\mathrm{C}$, and twenty one in line $\mathrm{B}$, were chosen from the two dimension sectional views. Fig. 4 shows the methods used for calculating the VSS and NHE rates from the mean values of the forty three data points. The VSS and NHE rate were calculated using the following equations:

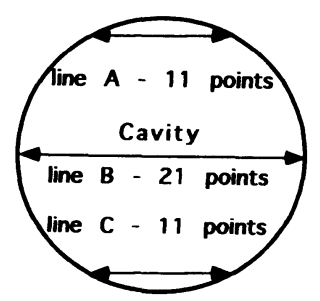

Fig. 3 Three lines were used to obtain forty three data points. The length of lines $\mathrm{A}$ and $\mathrm{C}$ were about half that of line $B$. 


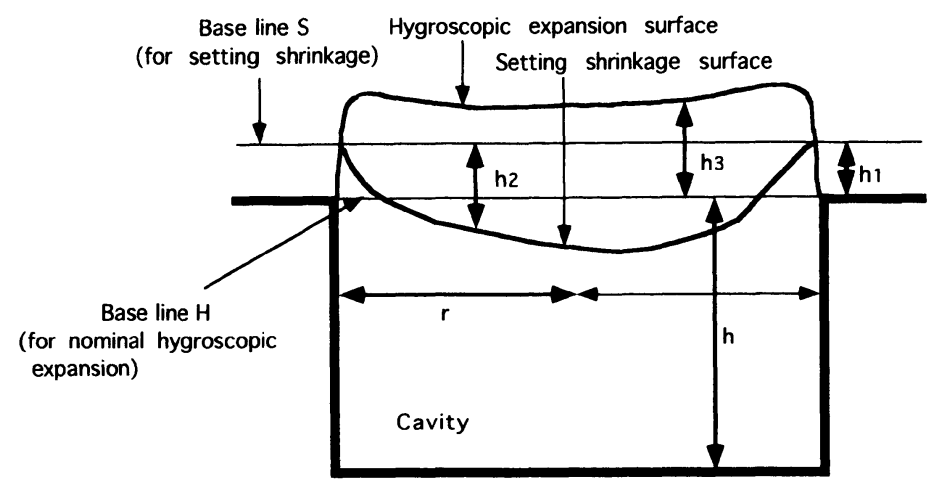

Fig. 4 Schematic illustration showing how to calculate volumetric setting shrinkage and hygroscopic expansion.

h: Depth of cavity

$\mathrm{r}$ : Radius of cavity

$h_{1}$ : Thickness of overfilled cement

$\mathrm{h}_{2}$ : Average depth from base line $\mathrm{S}$ to setting shrinkage surface

$h_{3}$ : Average height from base line $H$ to hygroscopic expansion surface

VSS rate $(\operatorname{vol} \%)=\left\{\left(\pi \cdot \mathrm{r}^{2} \cdot \mathrm{h}_{2}\right) /\left[\pi \cdot \mathrm{r}^{2} \cdot\left(\mathrm{h}+\mathrm{h}_{1}\right)\right]\right\} \times 100$

$$
=\left[h_{2} /\left(h+h_{1}\right)\right] \times 100
$$

NHE rate $(\operatorname{vol} \%)=\left\{\left[\pi \cdot r^{2} \cdot\left(h_{3}-h_{2}\right)\right] /\left[\pi \cdot r^{2} \cdot\left(h+h_{1}\right)\right]\right\} \times 100$

$$
=\left[\left(h_{3}-h_{1}\right) /\left(h+h_{1}\right)\right] \times 100
$$

Where $\mathrm{h} \sim \mathrm{h}_{3}$ and $\mathrm{r}$ are defined as follows:

h: depth of cavity;

$h_{1}$ : thickness of the overfilled cement;

$\mathrm{h}_{2}$ : average depth of forty three data points from the baseline $\mathrm{S}$ to setting shrinkage surface;

$h_{3}$ : average height of forty three data points from the baseline $H$ to hygroscopic expansion surface;

$r$ : radius of cavity.

In addition, we thought that the real hygroscopic expansion is not NHE but sum value between NHE and VSS, because hygroscopic expansion started after polymerization shrinkage had occurred. So, the volumetric hygroscopic expansion (VHE) rate was obtained by subtraction between the NHE and VSS rates (VHE $=$ NHE - VSS) for the VSS rate was defined with a minus value in this study.

Three specimens were measured for each cavity group, and the mean values are presented. The results were analyzed statistically by one-way ANOVA for the dimensional changes $(\mathrm{P}=0.05)$, and Pearson's correlation coefficient for the regression coefficient $(\mathrm{P}<0.01)$. 


\section{RESULTS}

\section{Volumetric setting shrinkage}

Fig. 2(a) shows the behavior of setting shrinkage. All specimens showed increasing setting shrinkage from the cavity margin to the center portion of the free surface.

The VSS rate in the different $\mathrm{C}$-value groups and significant differences among the experimental groups are shown in Fig. 5(a) and Table 3(a). The VSS rate decreased with increasing C-value, and the group of 2.0 showed the largest value. There were no significant differences between the same $\mathrm{C}$-value groups although their cavity

C-value

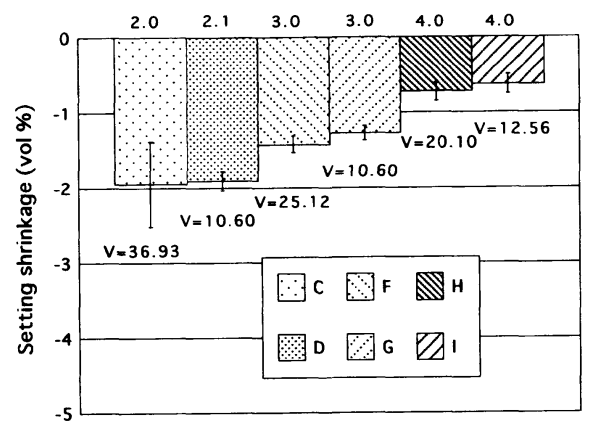

(a) Between volumetric setting shrinkage and cavity $\mathrm{C}$-value

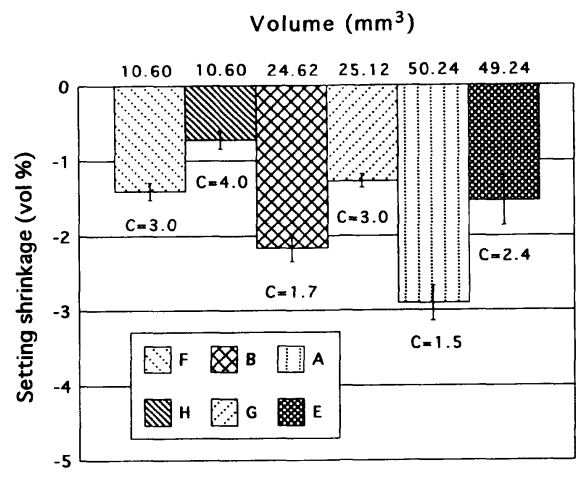

(b) Between volumetric setting shrinkage and cavity volume

Fig. 5 Volumetric setting shrinkage in different C-value and cavity volume groups.

A to I: type of cavity

$\mathrm{V}$ : the volume of cavity

$\mathrm{C}$ : the $\mathrm{C}$-value of cavity

Table 3 Results of one way ANOVA of volumetric setting shrinkage and hygroscopic expansion

(a) Volumetric setting shrinkage

\begin{tabular}{|c|c|c|c|c|c|c|c|c|}
\hline & $\mathrm{A}$ & B & $\mathrm{C}$ & $\mathrm{D}$ & $\mathrm{E}$ & $\mathrm{F}$ & $\mathrm{G}$ & $\mathrm{H}$ \\
\hline B & * & & & & & & & \\
\hline $\mathrm{C}$ & * & & & & & & & \\
\hline D & $*$ & & & & & & & \\
\hline $\mathrm{E}$ & * & * & & & & & & \\
\hline $\mathrm{F}$ & * & * & * & * & & & & \\
\hline $\mathrm{G}$ & * & $*$ & * & * & & & & \\
\hline $\mathrm{H}$ & * & $*$ & * & $*$ & $*$ & $*$ & $*$ & \\
\hline I & * & $*$ & * & $*$ & $*$ & $*$ & * & \\
\hline
\end{tabular}

(b) Volumetric hygroscopic expansion

\begin{tabular}{|c|c|c|c|c|c|c|c|c|}
\hline & A & B & $\mathrm{C}$ & $\mathrm{D}$ & $\mathrm{E}$ & $\mathrm{F}$ & $\mathrm{G}$ & $\mathrm{H}$ \\
\hline B & & & & & & & & \\
\hline $\mathrm{C}$ & $*$ & $*$ & & & & & & \\
\hline $\mathrm{D}$ & & & & & & & & \\
\hline $\mathrm{E}$ & & & & & & & & \\
\hline $\mathrm{F}$ & $*$ & $*$ & & & & & & \\
\hline $\mathrm{G}$ & $*$ & $*$ & & $*$ & & & & \\
\hline $\mathrm{H}$ & $*$ & $*$ & & & & & & \\
\hline I & $*$ & $*$ & $*$ & $*$ & $*$ & & & \\
\hline
\end{tabular}

*: Significant difference

A $\sim$ I: Cavity groups used in present study 


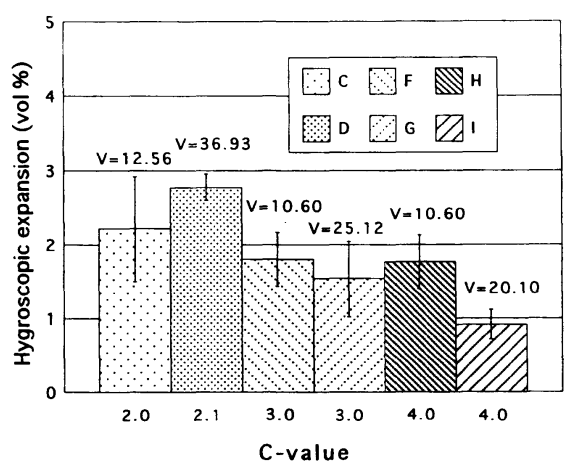

(a) Between volumetric hygroscopic expansion and cavity $\mathrm{C}$-value

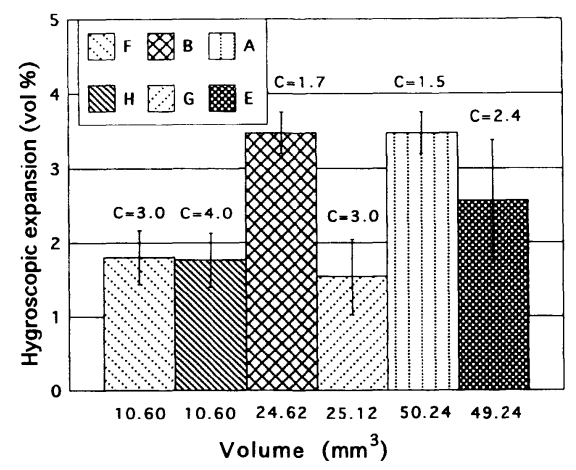

(b) Between volumetric hygroscopic expansion and cavity volume

Fig. 6 Volumetric hygroscopic expansion in different C-value and cavity volume groups.

A to I: type of cavity

$\mathrm{V}$ : the volume of cavity

$\mathrm{C}$ : the $\mathrm{C}$-value of cavity

volumes were different, but there were significant differences among the three other $\mathrm{C}$-value groups.

The VSS rate in the different cavity volume groups are shown in Fig. 5(b). It seemed that the VSS rate increased with increasing cavity volume. While there were no significant differences between the same $\mathrm{C}$-value groups, there were significant differences in the same volume groups. In addition, greater C-value specimens showed a smaller VSS rate between the same volume groups.

\section{Hygroscopic expansion}

As shown in Fig. 2(b), all specimens showed expansion at the end of $14 \mathrm{~d}$ water immersion. While the center of the free surface showed greater shrinkage than the margin ((Fig. 2(a)), on hygroscopic expansion, the center expanded more than the margin portion.

Fig. 6 shows the VHE rate with two parameters of different cavity C-values and cavity volumes. As the result in the VSS rate, the C-value of the 2.0 groups showed the largest VHE rate among the different C-value groups (Fig. 6(a)). And between the same cavity volume groups, the greater $\mathrm{C}$-value part showed the smaller value (Fig. 6(b)). Significant differences in the VHE rate among the experimental groups are shown in Table $3(\mathrm{~b})$.

\section{Regression analysis}

Fig. 7 shows the results of regression analysis between VSS, and the C-value (a) and cavity volume (b). Regression analysis indicated a high inverse correlation between the C-value and VSS $(r=0.92)$, but a low correlation between the cavity volume and 


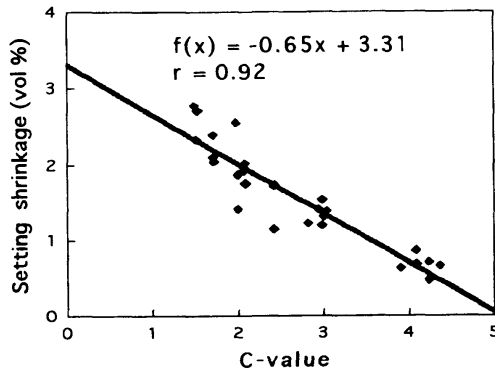

(a) Between volumetric setting shrinkage and cavity C-value

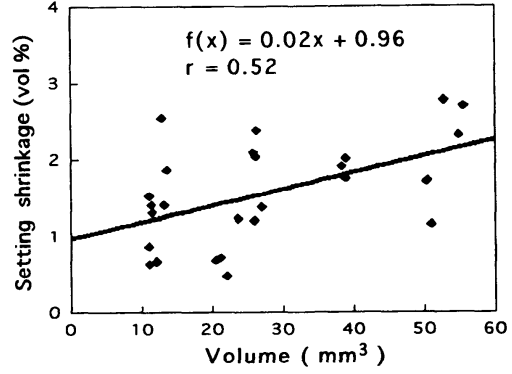

(b) Between volumetric setting shrinkage and cavity volume

Fig. 7 Results of regression analysis between volumetric setting shrinkage, and Cvalue and cavity volume.

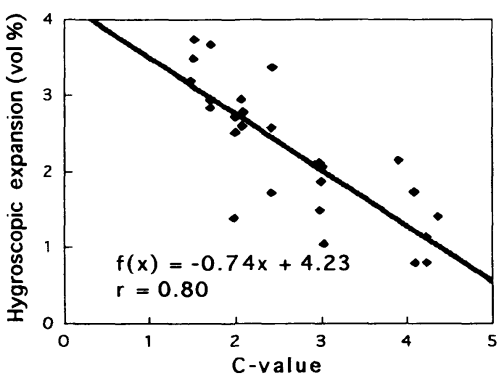

(a) Between volumetric hygroscopic expansion and cavity Cvalue

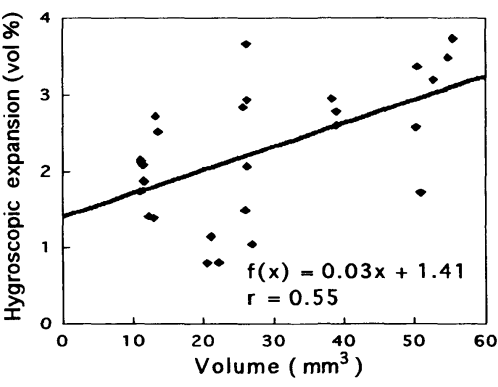

(b) Between volumetric hygroscopic expansion and cavity volume

Fig. 8 Results of regression analysis between volumetric hygroscopic expansion, and $\mathrm{C}$-value and cavity volume.

$\operatorname{VSS}(\mathbf{r}=0.52)$. The results of regression analysis between the VHE, and C-value (a) and cavity volume (b) are shown in Fig. 8. The C-value also showed a high inverse correlation to VHE $(r=0.80)$, as with VSS, and a high correlation coefficient compared with that of cavity volume $(\mathrm{r}=0.55)$.

\section{DISCUSSION}

To date, volumetric dimensional change values have been obtained from calculation of linear values ${ }^{21,28)}$ or with dilatometers $\mathrm{s}^{29,30)}$. However, these values were measured in non-filled condition, and can not be compared with restoratives in the cavity, which have clinical meaning. Therefore, in the present study, a non-contact three dimensional measurement apparatus was used to measure the dimensional changes of restoration in filled cavities. Furthermore, this method enables visualization of the results 
after measurement of dimensional change as shown in Fig. 2(a) and (b).

As shown in Fig. 2(a), the setting shrinkage increased from the cavity margin to the center of the free surface. This phenomenon could be explained by the restraining ability of the bonding surface. According to one study ${ }^{31}$, if there is no intact bonding between the cavity wall and resin composite, the composite will shrink in all dimensions. However, under intact bonding condition, the flow of the material is restrained by the bonding to cavity wall, and resulting in concentrated shrinkage in the center portion of the free surface. FJL has a high bonding ability to tooth substrates and shows a high setting shrinkage by incorporated $\mathrm{HEMA}^{4-7)}$. So, during the setting process, the flow was restrained by the cavity wall, and shrinkage became greater in the center than in the margin of the cavity.

On the other hand, in hygroscopic expansion, the center of the free surface showed greater expansion than the margin portion as shown in Fig. 2(b). This phenomenon could be explained by high hygroscopic expansion. During the setting process, the contraction stress was retained in the adhesive surface and the restorative material itself. However, that stress was compensated gradually with developing of the hygroscopic expansion ${ }^{9,14}$. And after the cancellation of stress, compressive stress on the cavity wall was generated ${ }^{9)}$. So, the excess expansion would be concentrated in the center portion of the free surface, and the center portion would show more expansion than the margin portion.

According to our results, there was a strong inverse correlation between the Cvalue and VSS rate as shown in Fig. 7 (a). So, in high $\mathrm{C}$-value cavities, the VSS rate is small and the contraction stress greater than in low $\mathrm{C}$-value cavities. Consequently, the risk of restoration failure would be greater with increasing C-value as discussed in previous studies ${ }^{1-3)}$. Therefore, it is very important that the bond is able to withstand the contraction stress during the setting process for the success of the restoration in high $\mathrm{C}$-value cavities.

The C-value also showed a strong inverse correlation with VHE rate as shown in Fig. 8(a). Therefore, it was also confirmed that there was a similar effect of $\mathrm{C}$-value on hygroscopic expansion as on setting shrinkage, that is, hygroscopic expansion become smaller with increasing $\mathrm{C}$-value.

As described in the results, the VSS rate was seemed to increase with increasing cavity volume. However, there were significant differences in VSS between the same cavity volume groups with different C-values (see Fig. 5(b) and Table 3(b)), though there were no significant differences between same $\mathrm{C}$-value groups with different cavity volumes (see Fig. 5(a) and Table 3(a)). While there was a high correlation between the C-value and VSS (Fig. 7(a)), the correlation between the cavity volume and VSS was low (Fig. 7(b)). These results suggest that the C-value has a more predominant effect on VSS than does cavity volume on, while the VSS rate seemed to increase with increasing cavity volume.

Between the VHE and cavity volume, although the cavity volume of $A$ and $G$ groups were twice that of $\mathrm{B}$ and $\mathrm{F}$ respectively, there were no significant differences in VHE (see Fig.6(b) and Table 3(b)). Additionally, there was a weak correlation 
between cavity volume and VHE as shown in Fig. 8(b). Through these results, it was also confirmed that the effect of cavity volume on VHE is small, and that VHE was mostly affected by the cavity C-value.

The factors which affect VSS and VHE on FJL filled cavities were clarified. The results of the present study have important implications for the durability of restorations in deep class $\mathrm{I}$ and $\mathrm{V}$ cavities which have high contraction stress due to their high C-value. As discussed previously, hygroscopic expansion would remove the residual contraction stress, and result in good marginal adaptability ${ }^{9,14}$. However, in high C-value cavities, high contraction stress remains at the initial stage of the setting process when the filled material is still being protected against water exposure, and the risk of adhesive failure between the cavity wall and RMGI would also be great. Therefore, it is very important to ensure that the bond is able to withstand the contraction stress during the initial stage of setting. As shown in our results, if the Cvalue becomes small, the bonding would be able to withstand against to the stress. The cavity C-value becomes greater with increasing cavity depth. Therefore, in the restoration of deep class $I$ and $V$ cavities, the incremental filling technique would be effective.

\section{CONCLUSIONS}

The effects of two parameters, C-value and cavity volume, on the VSS and VHE of RMGI in experimental cylindrical cavities were evaluated. The conclusions are as follows:

1. While the center of the cavity showed greater setting shrinkage than the margin, hygroscopic expansion caused overall expansion and greater expansion in the center than the margin portion.

2. The C-value showed strong correlations with VSS and VHE of FJL in experimental cylindrical cavities.

3. The effects of cavity volume on the VSS and VHE of FJL in experimental cylindrical cavity were small.

\section{ACKNOWLEDGMENTS}

The authors wish to express their appreciation to Professor Tadashi Hirasawa of Department of Dental Engineering, Tsurumi University School of Dental Medicine for his advice and encouragement. We would also like to express our appreciation to members of the same department for their helpful discussions.

Part of this study was presented at the 30th General Meeting of the Japanese Society for Dental Materials and Devices, September 20, 1997, Fukuoka, Japan, and at the 32th General Meeting of the Japanese Society for Dental Materials and Devices, October 18, 1998, Niigata, Japan. 


\section{REFERENCES}

1) Feilzer, A.J., De Gee, A.J. and Davidson, C. L.: Setting stress in composite resin in relation to configuration of the restoration, $J$ Dent Res 66(11) : 1636-1639, 1987.

2) Davidson, C. L. and De Gee, A. J.: Relaxation of polymerization contraction stresses by flow in dental composites, $J$ Dent Res 63(2) : 146-148, 1984.

3) Feilzer, A. J., De Gee, A. J. and Davidson, C. L.: Increased wall to wall curing contraction in thin bonded resin layers, J Dent Res 68(1): 48-50, 1989.

4) Sift, E. J., Mapawlus, Jr. and Vargas, M. A.: Shear bond strengths of resin-modified glass-ionomer restorative materials, Oper Dent $20: 138-143,1995$.

5) Lin, A., Mcintyre, N.S. and Davidson, R. D.: Studies on the adhesion of glass-ionomer cements to dentin, J Dent Res 71(11) : 1836-1841, 1992.

6) Young-gill, K., Hirano, S. and Hirasawa, T.: Physical properties of resin-modified glass-ionomer, Dent Mater J 17(1) : 68-76, 1998.

7) Attin, T., Buchalla, W., Kielbassa, A. M. and Hellwig, E.: Curing shrinkage and volumetric changes of resin-modified glass-ionomer restorative materials, Dent Mater 11 : 359$362,1995$.

8) Nitta, Y.: Effect of surface treatment on microleakage and tensile bond strength of glass polyalkenoate cement, Japan J Conserv Dent 35(6) : 1346-1373, 1992. (in Japanese)

9) Feilzer, A.J., Kakaboura, A.I., De Gee, A.J. and Davidson, C. L.: The influence of water sorption on the development of setting shrinkage stress in traditional and resinmodified glass-ionomer cements, Dent Mater 11 : 186-190, 1995.

10) Shidu, S. K.: Marginal contraction gap formation of light-cured glass-ionomers, $A m J$ Dent $7: 115-118,1994$.

11) Davidson, C. L., Van Zegnbroeck, L. and Feilzer, A. J.: Destructive stresses in adhesive luting cements, J Dent Res 70(5):880-882, 1991.

12) Van Zeghbroeck, L. M. and Davidson, C. L.: Cohesive failure due to contraction stress in glass-ionomer luting cements, J Dent Res 68 : 1014, Abst. No.1180, 1993.

13) Irie, M. and Nakai, H.: Gaps between cavity margin and class V restoration made from three types of glass-ionomer, $J J$ Dent Mater 15(1): 138-143, 1995. (in Japanese)

14) Irie, M. and Nakai, H.: Marginal selability of resin-modified glass-ionomers for base/ liner: effect of hygroscopic expansion and bond strength, Dent Mater $J$ 15(2): 193-200, 1996.

15) Shidu, S. K., Sherriff, M. and Watson, T.F.: The effects of maturity and dehydration shrinkage on resin-modified glass-ionomer restorations, J Dent Res 76(8) : 1495-1501, 1997.

16) Watson, T.F. and Billington, R. W.: The interfacial region of the tooth/glass-ionomer restoration: a confocal optical microscope study, Am J Dent 4(6) : 303-310, 1991.

17) Watson, T. F.: A confocal microscopic study of some factors affecting the adaptation of a light-cured glass-ionomers to tooth tissue, $J$ Dent Res 69(8) : 1531-1538, 1990.

18) Friedl, K. H., Powers, J. M. and Hiller, K. A.: Influence of different factors on bond strength of hybrid ionomers, Oper Dent $20: 74-80,1995$.

19) Uno, S., Finger, W. J. and Fritz, U.: Long-term characteristics of resin-modified glassionomer restorative materials, Dent Mater $12: 64-69,1996$.

20) Bell, R. B. and Barkmeier, W. W.: Glass-ionomer restoratives and liners: shear bond strength to dentin, $J$ Esthet Dent 6(3): 129-134, 1994.

21) Kanchanavasita, W., Pearson, G. J. and Anstice, H. M.: Influence of humidity on dimensional stability of a range of ion-leachable cement, Biomaterials 16(12): 921-929, 1995.

22) Irie, M. and Nakai, H.: Effect of immersion in water on linear expansion and strength of three base/linear materials, Dent Mater $J$ 14(1): 70-77, 1995.

23) Yoshikawa, T., Hirasawa, M., Tosaki, S. and Hirota, K.: Concentration of HEMA eluted from light-cured glass ionomers, $J$ Dent Res 73(Special issue) : 133, Abstr. No.254, 1994.

24) Swift E. J., Pawlus, M. A., Vargas, M. A. and Fortin, D.: Depth of cure of resinmodified glass-ionomer restoratives, $J$ Dent Res 74(Special issue) : 38, Abstr. No.212, 
1995.

25) Jevnikar, P., Jarh, O., Sepe, A., Pinter, M. M. and Funduk, N.: Micro magnetic resonance imaging of water uptake by glass-ionomer cements, Dent Mater 13:20-23, 1997.

26) David, C.S. and Sumit, R.: The effect of water on polymer matrix and composite wear, Dent Mater $10: 6-10,1994$.

27) Condon, J.R. and Ferracane, J.L: In vitro wear of composite with varied cure, filler level, and filler treatment, $J$ Dent Res 76(7): 1405-1411, 1977.

28) De Gee, A. J., Feilzer, A. J. and Davidson, C. L.: True linear polymerization shrinkage of unfilled resins and composites determined with a linometer, Dent Meter $9: 11-14,1993$.

29) De Gee, A.J., Feilzer, A.J. and Davidson, C. L.: Setting shrinkage of resin-modified glass-ionomers light-cured at different moments after mixing, Third international congress on dental materials : 252, 1997.

30) Lai, J.H. and Johnson, A. E.: Measuring polymerization shrinkage of photo-activated restorative materials by a water-filled dilatometer, Dent Meter 9 : 139-143, 1993.

31) Versluis, A., Tantbirojn, D. and Douglas, W. H.: Do dental composites always shrink toward the light?, J Dent Res 77(6): 1435-1445, 1998. 